\title{
THE SWIMMING AND BURROWING HABITS OF SOME SPECIES OF THE AMPHIPOD GENUS BATHYPOREIA
}

\author{
By E. Emrys Watkin, B.Sc., Ph.D. \\ Lecturer in Zoology, University College of Wales, Aberystwyth \\ (Text-figs. I-2)

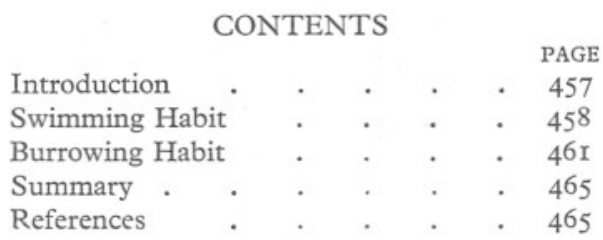

\section{INTRODUCTION}

The amphipod family Haustoriidae is represented in the coastal waters of Great Britain by three genera, Haustorius, Urothoë and Bathyporeia, all three of which are characterized by the habit of burrowing into the soil of the sea floor. Dennell (1933) deals at some length with the swimming and burrowing habits of Haustorius arenarius in which he shows that (p. 387) "the animal swims on its back by the beating of the powerful pleopods...burrowing is a modification of the swimming movements, and is dependent on the expulsive action of the swimming current". Crawford (1937), referring to the burrowing Amphipoda of certain soils of the sea bottom near Plymouth, states (p. 638), "The local Haustoriidae burrow almost entirely by ejecting sand grains in a powerful swimming current", and in giving some details of the burrowing of Urothoë brevicornis and U. grimaldii var. poseidonis states that it is very similar to that of Haustorius. Schellenberg (1929), in dealing with the burrowing habits of some amphipods, gives an outline description of the process in Bathyporeia robertsoni Bate (probably B. sarsi Watkin, 1938). The author in this paper shows that the swimming and burrowing habits of four species of Bathyporeia, namely, guilliamsoniana (Bate), elegans Watkin, pelagica (Bate) and pilos $a$ Lindström, are alike and similar to that of $B$. robertsoni as described by Schellenberg, but the process is described in much further detail. The burrowing habit differs considerably from that described by Dennell in Haustorius, in that it is dependent upon the sweeping action of the second gnathopods and first and second peraeopods aided by the first and second uropods; the swimming current takes no part in the process. The method of burrowing is more similar to that of Ampelisca which Crawford 
(1937) states (p. 638) "is not dependent on a flow of water set up by the pleopods but is performed by the scraping and hauling of the gnathopods, aided by the urosome as soon as it gets a purchase".

\section{Swimming Habit}

Movement has been observed in the four species guilliamsoniana (Bate), elegans Watkin, pelagica (Bate) and pilosa Lindström. No differences between the movement of the four species were observed. There are two types of movement, swimming and burrowing, which may follow each other in rapid
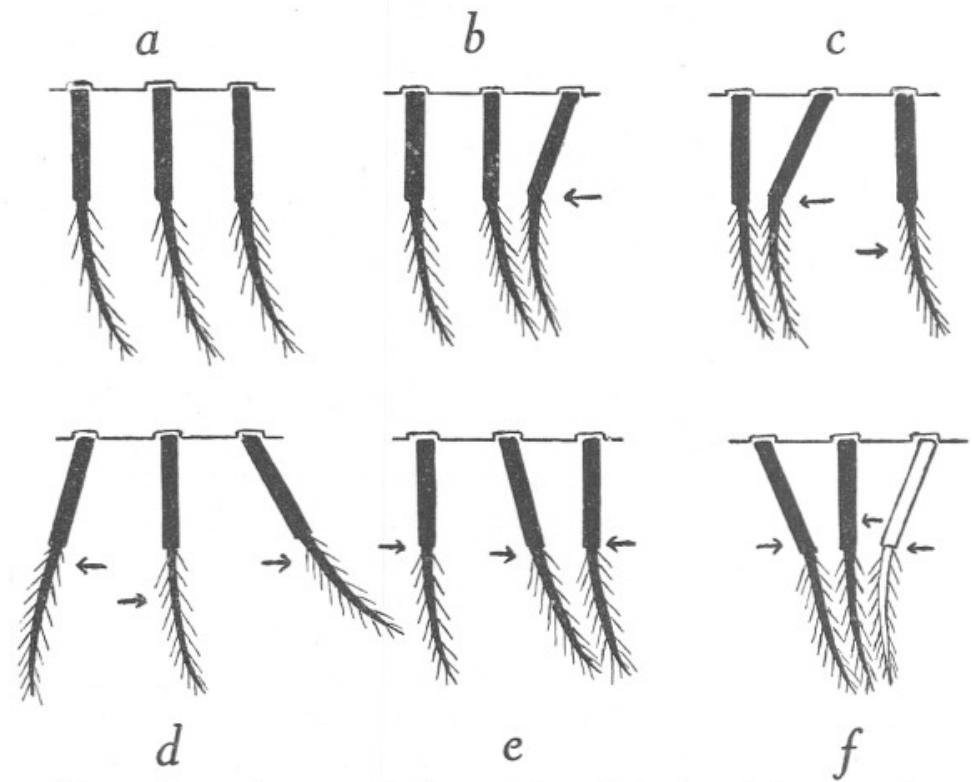

Fig. I. Successive stages in the metachronal rhythm of the pleopods.

succession. Swimming movements are effected by the pleopods. During this type of movement the body is held rigid and fully extended, the flagella of the antennules and antennae are laid back alongside the body, the pleon is fully extended which brings the first and second uropods close up beneath it, the third uropods depressed and in line with the pleon and converged in the median line (Fig. 2a). Thus a definite "stream-lining" effect is obtained.

Pleopod movement is of the metachronal type. At rest the three pairs of pleopods are held hanging vertical to the pleon, and each pair is capable of a forward and backward movement from the rest position. Fig. I $a$ shows diagrammatically the rest position. Swimming commences with a forward movement of the third pair (b). The second pair now begin their forward movement and the third pair begin their backward movement and are now in the vertical position 
thus an inter-limb space is created between the second and third pairs and water flows in to fill this space $(c)$. The first pair now commence their forward movement, the second pair have moved back to the vertical position, whilst the third pair are at the end of their backward stroke $(d)$. Thus an inter-limb space is created between the first and second pairs and water flows in to fill this space. The first pair now begin the backward movement, the second pair have completed the backward stroke and the third pair are recovering to the rest position (e). Thus water is forced out between the second and third pairs. The completion of the beat is shown in $(f)$ in which the first pair are at the end of their backward stroke, the second pair recovered to the rest position, whilst the third pair are moving forward for the next beat. Thus water is forced out from between the first and second pairs. Successive beats follow each other rapidly and the animal is driven forward through the water.

The rami of the pleopods are fringed with long feathered bristles (Fig. 2g). The bristles of the proximal end of the outer ramus are shorter and point outwards, those of the proximal end of the inner ramus are modified to serve as coupling hooks. The latter bristles have bifid tips with spear-shaped ends $\left(g_{2}\right)$ and between the bifid tip the corresponding bristles of the opposite pleopod fit. The interlocking bristles can move freely within each other but cannot be withdrawn, due to the spear-shaped tips. The pleopods of a pair are further linked together by coupling hooks on the distal end of the basal joint $\left(g_{1}\right)$. There are normally two coupling hooks on each basal joint, each with three recurved hooks into which the corresponding hooks of the opposite pleopod fit.

As a result of swimming movements currents of water are drawn in between the appendages and thus over the gills. The joints of some of the appendages are expanded and modified to form a ventral groove in which the gills are protected and in which in the female the brood pouch is formed. Anteriorly this groove is formed by the large coxal plates of the second peraeopods, the coxal plates of the second gnathopod and the first peraeopod lie alongside the mouthparts and are protective to them. Thus the ventral groove begins in the region of the second peraeon segment. The coxal plates of the third, fourth and fifth peraeopods are small and take no part in the formation of the ventral groove; their reduction is compensated by the expansion of some of the joints of these appendages. Peraeopod 3 is a doubly geniculate appendage, the basis is expanded and lies normally beneath its segment, the ischium is small and the large expanded merus is held at an angle of less than $90^{\circ}$ to the basis and thus comes to lie partly at the side and partly posterior to it. The expanded basis of peraeopod 4 continues the side of the groove and it is completed by the basis of peraeopod 5 which is expanded on its posterior margin only. Thus the ventral groove is a feature of the peraeon only.

The first epimeral plate of the pleon is small; between it and the basis of peraeopod 5 is a space through which the water from the ventral groove passes out. The second and third epimeral plates are well developed, the 

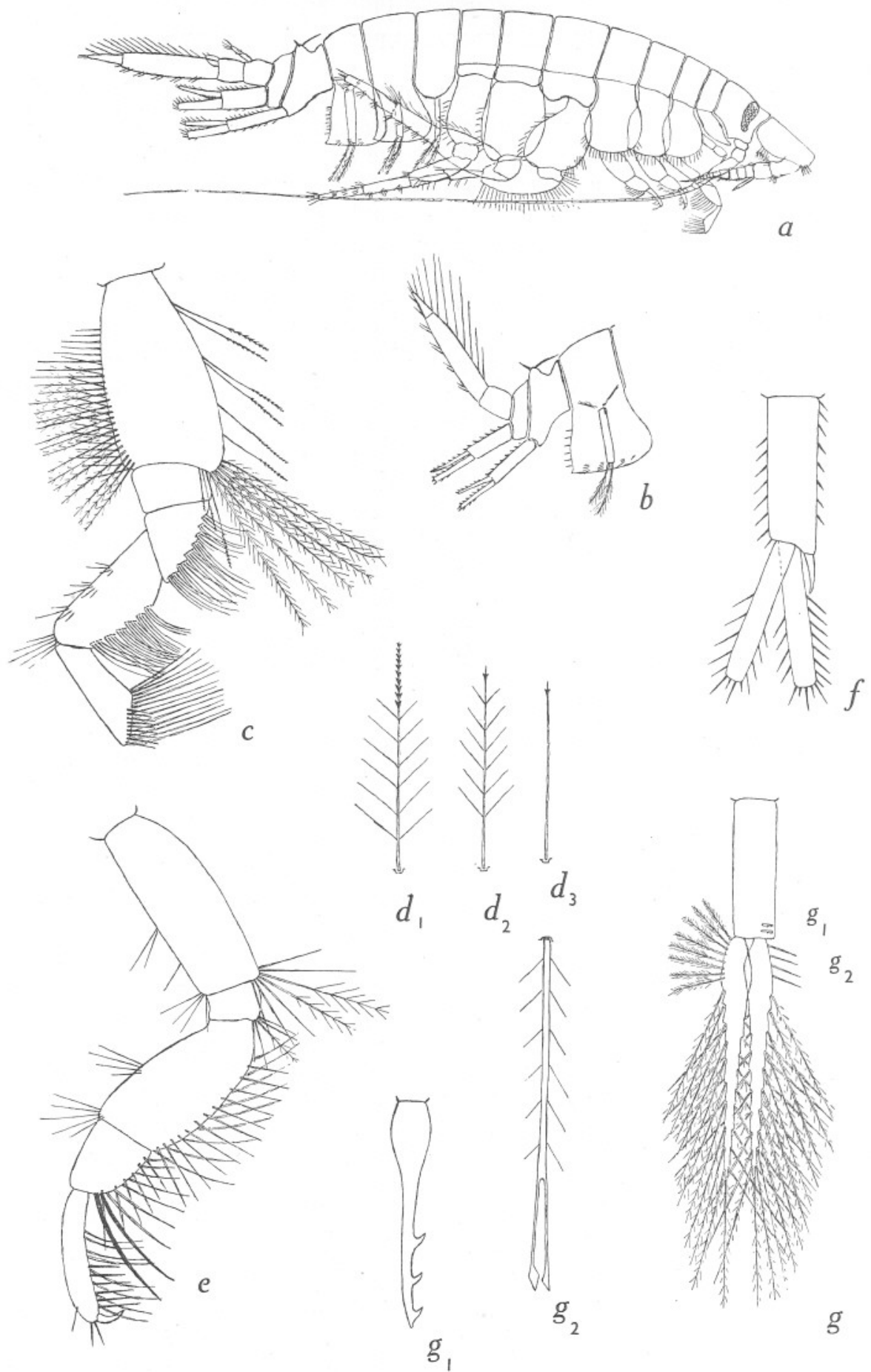

$g$,

$g_{2}$

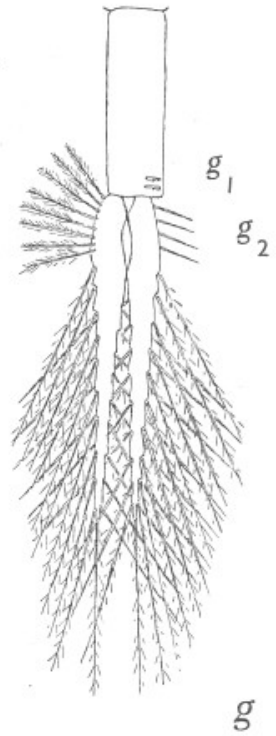

Fig. 2. Drawings based on Bathyporeia guilliamsoniana (Bate): a, animal in the swimming position; $b$, urosome in the burrowing position; $c$, second gnathopod; $d_{1}, d_{2}, d_{3}$, armature of bristles on anterior border of merus and carpus of the second gnathopod; $e$, first peraeopod; $f$, first uropod; $g$, pleopod; $g_{1}$, coupling hook on basal joint; $g_{2}$, modified feathered bristle from base of inner margin of inner ramus. 
second is convex anteriorly and concave posteriorly, the third typically rounded at both ends. Between the epimeral plates the pleopods work in unison to draw water through the ventral groove, and the urosome bends forward to push sand particles backwards beyond the animal.

Two main water currents are drawn into the ventral groove. The main current enters anteriorly between the second gnathopods. This current passes in well beneath the mouthparts; there is no evidence that any part of it is deflected on to the mouthparts and thus no evidence of feeding on small particles held in suspension in the water current. The entrance to the ventral groove is guarded by a series of long heavily feathered bristles which arise from the distal end of the basis of the second gnathopod; they form an effective filter for the larger particles suspended in the water current. A subsidiary water current is drawn in between the anteriorly directed second peraeopod and the backwardly directed third peraeopod. This opening is guarded by an extensive development of feathered bristles along the anterior margin of the basis, ischium and merus of peraeopod 3 , and the water current is thus filtered of the larger particles in suspension. The feathered bristles are directed inwards, and although those of the opposite sides do not meet they form an effective filter for practically all the water that enters at this point.

\section{BURROWING HABIT}

The second type of movement is that of burrowing into the sand which is the natural home of the species in this genus. Evidence is now available to show that the various species feed by cleaning sand particles and that swimming is a diversion probably connected mainly with reproduction when the tide covers them. They thus resemble in their habits certain cumaceans (Foxon, 1936) which live in the same type of habitat, and in some localities, e.g. Kames Bay, Millport, may be found in the same samples.

It has been shown that in the swimming movement the body is held rigid and fully extended with the pleon in line with the rest of the body, the first and second uropods laid back beneath the urosome, the third uropods extended and in line with the pleon and with their right and left rami converged to the middle line. The rami can be easily diverged from each other and it is suggested, although proof is difficult to obtain, that they may act as steering organs. The swimming movement eventually carries the animal head first into the sand when swimming ceases and burrowing begins. Penetration of the sand is assisted by the form of the antennule. The basal joint is large and extends forward in direct line with the head, with its proximal end broad and narrowing to the distal end, which thus is spear-shaped when viewed from above and acts as a ploughshare to penetrate the sand. The distal end of this basal joint carries a group of spines which point outwards in the direction in which the animal enters the sand. The second joint arises from the underside of the basal joint, and the whole limb beyond the basal joint can be laid back 
alongside the body. Similarly, the antenna can be laid back alongside the body, so that the anterior end of the body is triangular when viewed from the side and above, making rapid penetration of the sand an easier matter. The force of the swimming movement is sufficient to carry the head end into the sand and thus to bring the sand within reach of the burrowing appendages, which are the second gnathopods and first and second peraeopods. These three pairs of appendages are so arranged that the second gnathopods lie parallel with each other in the median plane; the first peraeopods diverge somewhat and come to lie outside and somewhat posterior to the second gnathopods; the second peraeopods also diverge and come to lie outside and somewhat posterior to the first peraeopods. The first gnathopods are small and are used as feeding appendages and are intimately associated with the mouthparts; thus the area beneath the head is free for the action of the burrowing limbs, which are flexed at the ischium and can be projected forward and drawn back with rapidity. The second gnathopods can extend forward to beneath the antennules; they sweep the sand particles backwards to within reach of the first and second peraeopods, which sweep the sand backwards towards the posterior end of the animal where it comes within reach of the first and second uropods. The three anterior burrowing limbs do not work in unison, the second gnathopod has a more rapid action than the peraeopods, all three, however, take a deep backward sweep before being drawn upwards and pushed forward for the next sweep.

Associated with the second gnathopods and first and second peraeopods in the burrowing movement are the first and second uropods. They, by means of flexion and extension of the pleon, sweep sand particles backwards beyond the animal. The pleon is flexed between the third and fourth segment. As a result of the flexion of the pleon the first and second uropods are carried forward, but the more delicate third uropods are raised into a vertical plane and are thus removed from the sphere of action of the first and second uropods (Fig. I $b$ ). The outer rami only of the third uropods are well developed and their inner margin is fringed with an edge row of long feathered bristles. The rami can be diverged from each other, and when held in the vertical position on the flexion of the pleon they are always widely separated. They thus act as a brake on the rapidity of the forward movement.

It is instructive to observe the animal attempting to burrow in very shallow sand in a dish, thus imitating and prolonging the first movements in the burrowing process. The abdomen is held in extension and sand particles are shot backwards beyond the animal from the second gnathopods and first and second peraeopods, being caught in the water issuing in the swimming movement from the ventral groove. This movement continues until full swimming in the water recommences. When the animal enters sand sufficiently deep to cover the body the first sweeps of the anterior burrowing appendages cause the sand particles to be flung back in the same way, but as the weight of sand to be moved becomes greater the rate of movement is reduced, the 
pleon is flexed, the first and second uropods come into service and the third uropods are raised, further reducing the speed of forward movement which now becomes a crawl through the sand. When the animal is placed on dry sand no attempt is made to burrow, but when the sand is damped but not covered with water penetration can be effected. On substituting mud for the sand no attempt is made to burrow, the animal swims round spasmodically and mud particles accumulate on the appendages.

The first and second uropods are robust appendages with the two rami of about equal length with no linking apparatus between the basal joints of a pair. The rami usually converge, but in the backward sweep, i.e. pleon extension, they diverge and thus cover a greater area, the arrangement of spines on their margins closing the gap between them. On the flexion of the pleon they converge and can thus be drawn back freely. The first uropods are longer than the second pair and work to the outside of them, thus sweeping sand away from underneath the whole width of the pleon.

The function of the third, fourth and fifth peraeopods in the burrowing process is somewhat doubtful, although some of their functions seem clearly indicated. It has already been shown that the basis of the three limbs and the merus of peraeopod 3 take part in the formation of the ventral groove. The merus of peraeopod 3 is fringed on its outer face near the anterior border with a row of spines which project outwards at right angles to the face of the joint. Their function is to prevent sand particles falling from above on to the edge row of feathered bristles of the merus which filters the water current entering at this point. The carpus and propodus of peraeopod 3 are reduced, geniculate to the merus and held alongside the body outside the expanded basis of peraeopod 4. The outer edge of the propodus carries a row of spines held at right angles to the outer face of the joint, and thus they also prevent sand particles from falling from above. The basis of peraeopod 4 is held normally beneath its segment, but from the ischium the limb is flexed to be held alongside the body outside peraeopod 5 and pointing dorsally and posteriorly, and diverging outwards. It is capable of a slight up-and-down and back-and-fore movement. Its main function seems to be the prevention of sand particles from falling from above; the inner face of the joint carries a group of spines and bristles which extend across the space between it and the body. It may assist burrowing by a forward push against the sand particles. Peraeopod 5 is also flexed at the ischium and is held pointing downwards and backwards. In its armature it carries a less number of bristles but a greater number of spines. This appendage from its position cannot prevent sand particles from falling from above; it may prevent sand particles falling inwards from the sides or possibly help to push the animal forward through the sand.

A detailed description of the second gnathopod, first and second peraeopods and first and second uropods will assist an understanding of the way in which these appendages are modified to serve the burrowing process. 
Second gnathopod (Fig. 2c). The basis is rectangular in outline; the anterior edge carries a row of simple bristles, the outer face a row of heavily feathered bristles, the inner face a row of serrated bristles, the posterior edge a few long serrated bristles. The distal edge of this joint carries a row of long feathered bristles, which together with those of the opposite limb form an effective filter to prevent large particles entering the ventral groove along with the main water current which enters through them. The ischium is small and square with a tuft of feathered bristles and simple bristles on its distal posterior edge; the feathered bristles assist in filtering the water current. The merus, carpus and propodus project forwards. The merus is triangular with up to seven groups of bristles on its posterior margin, each group is horseshoeshaped, the end bristles of each group are simple bristles $\left(d_{3}\right)$, the centre ones serrated feathered bristles $\left(d_{1}\right)$ with feathered bristles in between $\left(d_{2}\right)$. The carpus has a curved posterior edge which carries up to seven groups of bristles as on the merus. The anterior edge of the carpus carries about four groups of simple bristles. The propodus is spatulate with the ventral surface deeply grooved; the edges of the groove carry a row of well-developed spines which are fundamentally arranged on the same horseshoe-shaped pattern as on the merus and carpus, but the rows are broken by the hollow ventral surface. On the outer edge at the distal end is a row of about twelve stout spines. The bristles on the merus, carpus and propodus are curved backwards to assist in the process of sweeping the sand particles. The dactylus is absent.

The first peraeopod (Fig. 2e) is stoutly built with the basis rectangular with a few serrated bristles and ordinary bristles on the anterior margin near the base and with a few feathered bristles and ordinary bristles near the apex. The feathered bristles assist in filtering the water current entering the ventral groove. The ischium is small and square. The merus and carpus are broad with an inner face row and outer face row of simple bristles on the anterior margin. The distal end of the anterior margin of the carpus bears a pair of much stronger spines with two other spines not so well developed. These strong spines are somewhat hooked and are the main sweeping structures on this appendage. The merus and carpus are somewhat geniculate to the ischium. The propodus is smaller, not swollen, with the anterior edge carrying a row of spines and the outer and inner faces with a row of bristles. The dactylus is claw-like. The inner and outer face rows of bristles on the merus, carpus and propodus extend laterally to aid the sweeping movement. The absence of heavily feathered bristles show this appendage to be mainly sweeping in function and not assisting to any extent in filtering the water current entering the ventral groove.

The second peraeopod is built on the same plan as the first with the same armature; the only comment necessary is that the spines of the edge row on the propodus are stronger.

The first and second uropods (Fig. $2 f$ ) are stoutly built with the basal joint carrying a row of small spines on outer and inner edges. The distal end of 
the outer edge carries a stout spine. The inner and outer rami are of equal length and the inner arises immediately dorsal to the outer. The inner and outer rami carry a row of stout spines along their inner and outer edges and around the apex. The ventral surface carries a few scattered bristles.

This work was in part carried out at the Laboratory of the Scottish Marine Biological Association, Millport. My thanks are due to the Director, $\mathrm{Mr}$ Richard Elmhirst, for the facilities afforded me there.

\section{SUMMARY}

The swimming and burrowing habits of four species of the genus Bathyporeia have been examined and shown to be alike, and similar to B. robertsoni as described by Schellenberg.

Swimming is effected by the pleopods working in a metachronal rhythm, drawing water along a ventral groove formed by the coxal plates of the second peraeopods and the expanded bases of peraeopods 3,4 and 5 .

The main water current enters anteriorly between the second gnathopods and is filtered by a series of feathered bristles borne on the basis of this appendage; a subsidiary current enters between the second and third peraeopods.

Burrowing is effected mainly by the sweeping action of the second gnathopods and first two pairs of peraeopods, aided by the first and second uropods as soon as they can obtain a purchase on the sand. The adaptation of these three pairs of appendages to burrowing is explained.

The method of burrowing is different from that described by Dennell for Haustorius and appears to be more nearly related to that of Ampelisca.

\section{REFERENCES}

CRAWFord, G. I., I937. Notes on the distribution of burrowing Isopoda and Amphipoda in various soils on the sea bottom near Plymouth. Fourn. Mar. Biol. Assoc., Vol. xxi, p. 638.

Dennell, R., I933. The habits and feeding mechanism of the amphipod Haustorius arenarius Slabber. Fourn. Linn. Soc. Zool. London, Vol. xxxviII, p. 387.

Foxon, G. E. H., I936. Notes on the natural history of certain sand-dwelling Cumacea. Ann. Mag. Nat. Hist., Ser. Io, Vol. xvII, pp. 377-393.

SChellenBerg, A., I929. Körperbau und Grabweise einiger Amphipoden. Zool. Anz. Leipzig, Vol. Lxxxv, pp. I86-I90.

WatkIn, E. E., I938. A revision of the amphipod genus Bathyporeia Lindström. Fourn. Mar. Biol. Assoc., Vol. xxiII, pp. 21 I-236. 